\title{
O ESTADO DEMOCRÁTICO DE DIREITO E O PRINCÍPIO DA \\ DIGNIDADE HUMANA APLICADO ÀS NORMAS JURÍDICO \\ TRIBUTÁRIAS
}

THE DEMOCRATIC STATE OF LAW AND THE PRINCIPLE OF HUMAN DIGNITY APPLIED TO THE LEGAL LEGAL RULES

Recebimento em 03/10/2018

Aceito em 24/01/2019

Thaile Xavier Dantas ${ }^{1}$

Resumo: O Estado Democrático de Direito estabeleceu princípios constitucionais na seara tributária de grande valia, visto que o poder público está vinculado as suas limitações, não lhe competindo cometer abusos no exercício de sua atividade tributacional. A Constituição Federal consagra a dignidade humana como um dos fundamentos da República e tem por objetivos fundamentais a construção de uma sociedade livre, justa e solidária. Contudo, a imposição tributária desmedida vulnera os direitos fundamentais, motivo pelo qual o constituinte limitou os poderes dos entes públicos. O princípio da dignidade da pessoa humana estabelece os termos que asseguram ao cidadão a preservação do mínimo existencial que lhe permite viver em condições de igualdade e desenvolvimento através de planejamentos a serem desenvolvidos pelo próprio poder público.

Palavras-chave: princípio da dignidade da pessoa humana. contribuinte. tributação

Abstract: The Democratic State of Law established constitutional principles in the tax field of great value, since the public power is bound to its limitations, not competing to commit abuses in the exercise of the taxation activity.The Federal Constitution consecrates human dignity as one of the foundations of the Republic and has as fundamental objectives the construction of a free, fair and solidary society. However, excessive taxation violates fundamental rights, which is why the constituent has limited the powers of public entities. The principle of the dignity of the human person establishes the limits that assure to the citizen the preservation of the existential minimum that allows him to live in conditions of equality and development through plans to be developed by the own public power.

${ }^{1}$ Mestranda, advogada especialista em Direito Tributário 
Key-words: principle of the dignity of the human person. taxpayer. taxation

\section{INTRODUÇÃO}

O presente trabalho tem por objetivo identificar e analisar o basilar princípio constitucional da república brasileira, aplicado ao direito tributário, e seus aspectos mais relevantes.

Dessa forma, o artigo irá desenvolver o estudo a partir do princípio da dignidade humana e sua integração a estrutura do sistema jurídico relativamente ao tema proposto.

$\mathrm{Na}$ atualidade do país, se faz necessária a discussão acerca dos direitos fundamentais, visto que são tais direitos que contem o poder do Estado, limitando suas ações.

O estudo se inicia com uma exposição acerca da evolução constitucional queinstituiu em 1988 o Estado Democrático de Direito, traduzindo seu conceito e importância. Tal modelo constitucional, positivou os direitos fundamentais, assegurando a todos os cidadãos condições mínimas de existência, conferindo ao Estado o dever de proteção efetiva ao rol de direitos elencados no artigo $5^{\circ}$, que não é taxativo e pode abranger outras posições não previstas formalmente no texto, mas que por sua relevância, são a eles equiparadas.

A seguir, o enfoque é o princípio da dignidade humana, servindo como elemento de proteção dos direitos fundamentais contramedidas restritivas adotadas quer pela administração pública, quer pelo legislador, blindando os direitos fundamentais contra os abusos do Estado, que são de essencial relevância na esfera tributária.

Abordará a importância da proteção aos direitos e garantias individuais representados por princípios constitucionais, especificamente o princípio da dignidade da pessoa humana e seu desdobramento em matéria tributária.

Destaca-se a importância da função defensiva dos direitos fundamentais, bem como o caráter instrumental do tributo para a subsistência material do Estado. Comentam-se as limitações constitucionais ao poder de tributar, bem como traz apontamento acerca do tratamento conferido ao direito de propriedade.

A proposta do trabalho não é exaurir o tema, visto sua complexidade e amplitude no universo jurídico, mas se pretende realizar alguns apontamentos do ponto de vista do direito tributário a aplicação dos princípios constitucionais 
O modo pelo qual o trabalho será desenvolvido é pelo método hipotético dedutivo analisando o princípio da dignidade da pessoa humana dentro do sistema de direito positivo, especificamente a Constituição Federal, com uma perspectiva de aplicação pratica voltada ao direito tributário.

\section{A CONSTITUIÇÃO E O ESTADO DEMOCRÁTICO DE DIREITO}

Em uma sociedade política, a submissão dos homens a uma autoridade e anormas reguladoras da coexistência é inevitável. Esta autoridade é representada pelo Estado, ao qual compete atribuir direitos e deveres, bem como equilibrar os benefícios e encargos inerentes a vida social. É um sistema público de regras em que cada cidadão possui sua cota de participação.

O Estado possui variadas prerrogativas, entretanto, nenhum deles se sobrepõe aos valores da pessoa humana.

Na visão de Geraldo Ataliba (1998, p. 181) o advento da era constitucional, iniciada com a promulgação da Constituição norte-americana de 1787, fez com que a ação estatal fosse disciplinada de um lado pelo delineamento de poderes e de outro pela declaração de diversos direitos fundamentais. Assim, o Estado moderno é um Estado de Direito, regulado pelos preceitos da Constituição.

Segundo Lenio Streck e José Luiz Morais (2001, p. 86), no plano teórico, o Estado de Direito emergiu na Alemanha, na segunda metade do século XIX, como Rechtstaat, para ser posteriormente incorporado à doutrina francesa.

No Brasil, a Constituição Federal promulgada em 1988 declara a 'República' fundada na igualdade de todos os cidadãos perante a lei.

Ao declarar que a República Federativa do Brasil constitui-se em Estado Democrático de Direito (art. $1^{\circ}$ ), a Constituição institucionaliza um tipo de Estado que tem fundamentos e objetivos concretos (arts. $1^{\circ}$ a $3^{\circ}$ ). Segundo a doutrina pátria, o Estado Democrático constrói-se em torno de três pontos fundamentais: a) supremacia da vontade popular; b) preservação da liberdade, c) igualdade de direitos.

A objetivação dos direitos fundamentais, fruto da influência socializante, tem sempre em mira o homem inserido em um círculo de relações (BARZOTTO, 2005, p. 73).

Vinculado à ideia de democracia, tem na sua base o princípio da maioria, o princípio da igualdade e o princípio da liberdade. Entretanto, democracia é palavra que designa não apenas 
uma forma de governo, mas é entendida também como regime político, forma de vida e processo.

O reconhecimento de novos direitos fundamentais aos indivíduos de prestações sociais variadas, tais como assistência social, saúde, educação e trabalho, transportou os direitos que eram abstratos em direitos concretos.

Desta maneira, o Estado Democrático avançou em relação a busca por igualdade efetiva com intervenções que buscam assegurar aos cidadãos condições mínimas de vida. Assegurar o mínimo existencial é indispensável seja qual for a forma de organização social a ser implementada. Para John Rawls (1992, p. 218), sem o mínimo social, entendido como uma situação equitativa de oportunidades, não há fruição efetiva dos direitos de liberdade, bem como fica inviabilizada qualquer justiça distributiva. O mínimo existencial ou social constituiria, portanto, segundo o autor, verdadeira condição de liberdade.

Os direitos fundamentais são valores superiores a que o ordenamento constitucional conferiu aplicabilidade imediata, conforme o artigo $5^{\circ}$, parágrafo $1^{\circ}$. Desta forma não possuem cunho programático, sendo que o ente público não pode invocar a falta de regulamentação para obstar o exercício desses direitos. Ingo Sarlet (2004, p.91) explica que existem direitos materialmente fundamentais sem assento no texto constitucional, pelo que se conclui que o rol do artigo $5^{\circ}$, apesar de analítico, não tem cunho taxativo.

Fora do rol constitucional, há direitos fundamentais não expressamente positivados. Sendoimportante destacar que a teoria de direitos implícitos já se encontra sedimentada em nível doutrinário, com avanços também em nível jurisprudencial.

O Estado Democrático de Direito é traduzido pela limitação à arbitrariedade do poder político, pela submissão à lei, pelo estatuto constitucional dos direitos fundamentais e pelo comprometimento com a justiça, não admite o abuso dos direitos individuais como a produção de provas ilícitas, visando, contudo, validar os direitos humanos, as garantias individuais e não é condescendente com os interesses do governo autoritário.

A Constituição Federal de 1988, pela primeira vez na história, deu grande relevância aos direitos fundamentais. E em que pese a ausência de uma classificação adequada, como se verifica pela leitura do Título II, capítulos I a V, é nítido o pacto constitucional com os direitos fundamentais.

Pelo exposto, apresentamos uma definição de direitos fundamentais, elaborada pelo referido autor com suporte em Robert Alexy:

Direitos fundamentais são, portanto, todas aquelas posições jurídicas concernentes às pessoas, que, do ponto de vista do direito constitucional positivo, foram, por seu conteúdo e importância (fundamentalidade em sentido 
material), integradas ao texto da Constituição e, portanto, retiradas da esfera de disponibilidade dos poderes constituídos (fundamentalidade formal), bem como as que, por seu conteúdo e significado, possam lhes ser equiparados, agregandose à Constituição material, tendo, ou não, assento na Constituição formal (aqui considerada a abertura material do catálogo) (SARLET, 2004, p.89).

O Estado Democrático de Direito sustenta-se, portanto, numa conciliação entre ética, direito e política, seja sobre o enfoque individual, seja considerando a sociedade em que ele vive. Devendo o Estado abster-se de quaisquer ingerências na esfera individual que sejam contrarias a dignidade pessoal. Veremos adiante, que principalmente em matéria tributária, a dignidade da pessoa humana quer preservar a sobrevivência do cidadão com o mínimo de decoro, visto que se verifica com frequência cada vez maior o seu desrespeito e ofensa, pois, por inúmeras vezes os tributos cobrados chegam ao ponto de desequilibrar ou impedir o livre desenvolvimento de sua personalidade e de seu desenvolvimento.

Expostasalgumas breves considerações é possível entender que a ordem jurídica brasileira introduzida pela Constituição Federal é resumidamente um sistema normativo concebido para proteger o homem e ditar condutas de integração social com ênfase na proteção á serie de direitos fundamentais inerentes ao cidadão.

\section{A CONSTITUCIONALIZAÇÃO DOS PRINCÍPIOS TRIBUTÁRIOS}

COÊLHO (2018) destaca que os países europeus de tradição jurídica romanogermânica, a que pertencemos pela filiação lusa, trazem em suas Constituições alguns princípios tributários, sempre poucos. Os que são Estados Federais colocam nas Cartas Políticas outros tantos princípios relativos à repartição das competências, inclusive tributárias. A Inglaterra, matriz do Common Law, em seus documentos históricos, os quais em conjunto formam a Constituição inglesa, igualmente, mas de maneira esparsa, agasalha alguns princípios sobre o exercício do poder de tributar. Os EUA, que nos inspiraram a República, o Presidencialismo, o sistema difuso de controle de constitucionalidade e a Federação (certo que imprimimos à Federação a nossa feição centralizante), tampouco são um país que se demora em cuidados justributários no corpo da Constituição.

O Brasil, ao contrário, da Inglaterra e Estados Unidos, inundou a Constituição com princípios e regras. Somos, indubitavelmente, o país cuja Constituição é a mais extensa e minuciosa, principalmente em tema de tributação. 
Nos atual Estado Democrático de Direito, a necessidade de uma tributação eficiente para fazer frente às demandas cada vez mais crescentes da sociedade, e a consecução de tal objetivo como a observância dos limites impostos pela ordem constitucional e os direitos e garantias individuais nela assegurados, é matéria de grande interesse e preocupação de todo o corpo social, notadamente pelo conteúdo que a discussão envolve, motivo de conflitos entre princípios e bens jurídicos protegidos constitucionalmente (BOGO, 2006).

De certo, as hipóteses de incidência tributária começam na Constituição Federal, sendo que a tributação sempre esteve presente no curso da história.

No exercício de sua soberania o estado exige que os indivíduos lhe forneçam os recursos de que necessita. O poder de tributar nada mais é que um aspecto da soberania estatal, ou uma parcela desta. Não se trata, todavia, de uma simples relação de poder. É relação jurídica, embora o seu fundamento seja a soberania do Estado (MACHADO, 2003).

Desde que o Estado abandonou sua posição de mero espectador e passou a intervir no domínio econômico e social, aumentou a utilização das finanças públicas como instrumento dessa intervenção. A primeira grande característica das finanças nos dias de hoje é o caráter intervencionista do Estado, pela via da tributação (JÚNIOR, 1995, p. 06).

Na seara tributária, é o Estado quem administra a arrecadação, pautados pela legalidade conferida pela Constituição Federal, voltada a gestão e aplicação dos recursos para a consecução das finalidades do Estado, que se resume a realização do bem comum.

O financiamento estatal feito pela sociedade ocorre por meio da tributação, que, nos modernos Estados constitucionais, está balizada em geral por dois marcos fundamentais. No primeiro, a segurança jurídica e a proteção dos direitos e garantias individuais representados por princípios constitucionais como o da liberdade, da legalidade, visando assegurar outros de idêntica origem constitucional, como o da autonomia da vontade e o da liberdade econômica. No segundo, o marco da tributação dá-se pela ideia de justiça tributária, traduzida no princípio da igualdade e no seu desdobramento na área tributária, a capacidade contributiva, que representa a medida da tributação que cada cidadão pode/deve suportar.

É motivo de preocupação no Direito Tributário a questão da legitimidade da imposição Estatal, sendo certo que esta só é encontrada onde houver respeito aos direitos fundamentais e aos princípios constitucionais, como forma de garantir a segurança jurídica, pois na relação jurídico-tributária, o cidadão é titular de inúmeros desses direitos fundamentais, só havendo tributo se houver lei. 
Para Ricardo Lobo Torres (2005), as limitações constitucionais, problema fundamental do Estado moderno, confundem-se, na velha tradição liberal americana, com o próprio conteúdo do Direito Constitucional.

Ao Estado cumpre, garantir, de um lado, os direitos e liberdades fundamentais, e, de outro, promover a efetivação dos direitos econômicos, sociais, culturais, ambientais, bem como o bem-estar, a qualidade de vida e a igualdade real entre os cidadãos, mediante a transformação de suas estruturas.

Nesse contexto, a propriedade e a tributação assumem grande importância.

O poder de tributar incide sobre os incisos XXII e XXIII do artigo $5^{\circ}$, da Constituição Federal. Esses dispositivos constituem o substrato econômico e social da imposição fiscal.

Ainda, matéria complementar é tratada mais adiante a partir do artigo 150, na Seção II denominada de "Das limitações do Poder de Tributar", na qual estão contidas essas normas que balizam o exercício do poder por parte do Estado, no que tange à tributação. É certo, como dito anteriormente, que essas limitações não se esgotam na mencionada seção constitucional, mas também é certo que nela se encontra sua maior concentração (BUFFON, 2009).

Ademais, é fundamental que o legislador aja de acordo com a estrita legalidade, ou seja, que os agentes públicos exijam os tributos nos estritos limites previstos na lei, sendo-lhe vedada a exigência de tributos sem que haja uma norma jurídica a qual autorize a referida exigência.

O principio da legalidade garante que nenhum tributo será instituído, nem aumentado, a não ser através de lei (artigo 150, I, CF). Temos no 150, inciso II, da Constituição Federal a garantia da igualdade perante a lei para fins de tributação.

No artigo 150, inciso III, alínea "a" da Constituição Federal, é vedada a retroatividade da lei, que deve passar a produzir efeitos somente em relação ao futuro.

Além disso, pelo princípio da anterioridade descrito no artigo 150, inciso III, alínea "b" da Constituição Federal, nenhum tributo será cobrado, em cada exercício financeiro, sem que a lei que o instituiu ou aumentou tenha sido publicada antes de seu início. Desse modo, a lei fiscal há de ser anterior ao exercício financeiro em que o Estado arrecada o tributo, garantindo o planejamento das atividades econômicas com segurança.

Ainda no rol do artigo 150 da Constituição Federal ainda temos o inciso IV que veda que a tributação tenha um caráter confiscatório, enquanto o inciso $\mathrm{V}$ do mesmo dispositivo assegura a liberdade de tráfego de pessoas ou bens, independentemente de exigência de tributos.

Em que pese os artigos 150 a 152 da Constituição Federal elencarem o núcleo essencial da cidadania fiscal, outros dispositivos também são importantes: o artigo 145 , parágrafo $1^{\circ}$, que proclama, em nome da justiça tributária, o princípio da capacidade contributiva; os artigos 153 , 


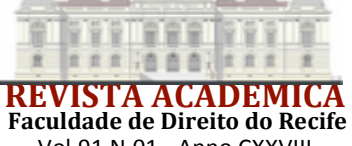

Faculdade de Direito do Recife

parágrafo $4^{\circ}$, 196 e 208, inciso I, que protegem o mínimo existencial; os artigos 153 a 156, sistematizadores da partilha tributária no federalismo brasileiro e, por isso mesmo, limitadores da atividade tributária. Há uma série de princípios que existem para proteger o cidadão contra os abusos do Estado.

Fundamental para completa exposição acerca do assunto, é expor acerca do direito de propriedade, que é uma garantia institucional e um direito fundamental, o qual incumbe ao Estado a promoção do bem estar social, e igualdade real entre os cidadãos, criando oportunidades aos menos favorecidos através de sua politica fiscal. Nesse sentido, é possível se considerar que cada vez mais um número maior e pessoas possam usufruir da propriedade ou de outros direitos patrimoniais, corrigindo desta forma, desigualdades na distribuição da riqueza.

O direito de propriedade está incluído entre os direitos e garantias fundamentais, nos termos do artigo $5^{\circ}$, inciso XXII que expressa ser garantido o direito a propriedade. Sem deixar de constar que o inciso XXIII obriga o proprietário a conferir a função social a sua propriedade.

Assim, a propriedade deve cumprir o fim a que se destina, sua proteção é condicionada à utilização produtiva dos bens, e no seu descumprimento o proprietário ficará sujeito às cominações legais.

O reconhecimento do direito de propriedade mantém, em relação ao dever de contribuição para o sustento do Estado, mediante o sistema tributário, uma relação de dependência recíproca (ROUSSEAU, 1958, p.23). É um paradoxo compreender que ao mesmo tempo em que a tributação confirma o direito de propriedade, acaba por limitá-lo.

Tal é a quantidade de normas e princípios tributários na Constituição Federal de 1988, que é considerada formadora do sistema tributário existente, de modo que o Direito Tributário não pode ser compreendido sem referência aos princípios elencados na Carta Magna.

Com efeito, a partir do artigo 145 da Constituição Federal, existe um título destinado à tributação e orçamento, no capitulo classificado "Sistema Tributário Nacional", expondo princípios, limitações, impostos e regras de repartição das receitas tributárias.

Como as leis tributárias são leis interventivas, mostra-se de particular importância a função defensiva dos direitos fundamentais, sem que isso implique, na presente análise, menosprezo às normas instituidoras de diretrizes positivas, tais como a dignidade humana. Nessa perspectiva, verifica-se que a garantia da propriedade é, sobretudo, uma diretriz da tributação e não apenas um limite ao poder de tributar (ÁVILA, 1999, p. 493).

Nos estados contemporâneos adeptos ao modelo de Estado Democrático de Direito,a dignidade da pessoa humanapassaa ser o fundamento para o desenvolvimento, planejamento e tomada de decisões e condutas do Estado em prol dos cidadãos. 


\section{O PRINCÍPIO DA DIGNIDADE DA PESSOA HUMANA NO ÂMBITO DO DIREITO TRIBUTÁRIO}

Em sua obra intitulada Fundamentação da Metafísica dos Costumes, o filósofo de Königsberg defende que as coisas não têm um fim em si mesmas mas o homem dever ser considerado como um fim, jamais como meio (GOMES, 2008, p. 277). Para Kant, enquanto coisas têm preço, a pessoa humana é dotada de dignidade, razão pela qual o homem jamais deverá ser coisificado, usado como meio.

Immanuel Kant explica a dignidade humana a partir da situação singular e natural do ser humano como ser racional e, bem por isso, dotado do exercício da autonomia da vontade, explicitado pela possibilidade de se autodeterminar e, também, agir conforme a representação de certas leis. A partir dessa nova concepção se inicia um processo de modificação da compreensão do sistema jurídico, elevando-se os direitos humanos e os direitos fundamentais a principais valores do ordenamento jurídico e da convivência humana.

É possível dizer que, segundo Luís Roberto Barroso e Ana Paula de Barcellos (BARROSO; BARCELLOS, 2003), o princípio da dignidade da pessoa humana identifica um espaço de integridade moral a ser assegurado a todas as pessoas por sua existência no mundo.

Segundo Paulo Luiz Netto Lobo:

A solidariedade e a dignidade da pessoa humana são os dois hemisférios indissociáveis do núcleo essencial irredutível da organização social, política e cultural e do ordenamento jurídico brasileiros. De um lado o valor da pessoa humana enquanto tal, e os deveres de todos para com sua realização existencial, nomeadamente do grupo familiar; de outro lado, os deveres de cada pessoa humana com as demais, na construção harmônica de suas dignidades. O princípio da solidariedade é o grande marco paradigmático que caracteriza a transformação do Estado liberal e individualista, do século XIX, em Estado Democrático e social, com suas vicissitudes e desafios, que o conturbado século XX nos legou. É superação do individualismo jurídico pela função social dos direitos. (Lobo, 2007, p.03)

A valorização dos princípios na ordem jurídica, principalmente a partir de sua constitucionalização e normatizações, traz inegavelmente a aproximação entre direito e moral.

O princípio da dignidade da pessoa humana significa o reconhecimento de que o Estado existe em função do homem, e não o contrário. Sendo o homem a finalidade precípua e não é mero meio da atividade estatal. 
A dignidade da pessoa humana concede unidade aos direitos e garantias fundamentais, sendo inerente às personalidades humanas. Esse fundamento afasta a ideia de predomínio das concepções transpessoalistas de Estado e Nação, em detrimento da liberdade individual. A dignidade é um valor espiritual e moral inerente à pessoa, que se manifesta singularmente na autodeterminação consciente e responsável da própria vida e que traz consigo a pretensão ao respeito por parte das demais pessoas, constituindo-se um mínimo invulnerável que todo estatuto jurídico deve assegurar, de modo que, somente excepcionalmente, possam ser feitas limitações ao exercício dos direitos fundamentais, mas sempre sem menosprezar a necessária estima que merecem todas as pessoas enquanto seres humanos (MORAES, 2006).

No Brasil, a Constituição Federal de 1988 é o marco do processo de democratização do Estado brasileiro, pois consolida a demarcação jurídica da transição de um regime ditatorial para um regime democrático, unificando todos os direitos fundamentais no princípio da dignidade. A dignidade da pessoa humana passa a figurar, no texto constitucional, como cláusula geral, apta a tutelar todas as situações envolvendo violações à pessoa, ainda que não previstas taxativamente norol do artigo $5^{\circ}$, tratam-se de direitos que podem ser equiparados ao direito formal, entretanto, fundamentais em razão de seu conteúdo.

Conforme Zulmar Fachin, a dignidade é, pois, um valor nuclear do ordenamento jurídico brasileiro. E, por óbvio, não poderia ser excluído do processo:

A dignidade da pessoa é princípio fundamental da República Federativa do Brasil. É o que chama princípio estruturante, constitutivo e indicativo das ideias diretivas básicas de toda a ordem constitucional. Tal princípio ganha concretização por meio de outros princípios e regras constitucionais formando um sistema interno harmônico, e afasta, de pronto, a ideia do predomínio do individualismo atomista do direito. Aplica-se como leme a todo o ordenamento jurídico nacional compondo-lhe o sentido e fulminando de inconstitucionalidade todo preceito que com ele conflitar. É de um princípio emancipatório que trata. (Fachin, 2010, p. 198)

Pode-se dizer que a Constituição Federal de 1988 foi a primeira na história do constitucionalismo pátrio a prever um título próprio destinado aos princípios fundamentais. A dignidade da pessoa humana é o fundamento de todo o sistema dos direitos fundamentais, no sentido de que estes constituem exigências, concretizações e desdobramentos da dignidade da pessoa e que com base nesta é que devem ser interpretados (CARVALHO, 2008).

Desta forma, o princípio da dignidade humana surge como construtor de uma nova cidadania, implementadora de políticas públicas nas áreas sociais, educacionais, previdenciárias, ambientais, de proteção às minorias e etc. Não se tratando de um mero valor moral. 
Ainda, insta frisar que as próprias normas constitucionais fazem referência à proteção do contribuinte, e se constituem o chamado Estatuto Mínimo de proteção. Esse mínimo essencial deve ser garantido pelo Estado.

Nesse sentido, os poderes públicos assumem a responsabilidade de proporcionar à generalidade dos cidadãos as prestações e serviços públicos adequados para garantir suas necessidades vitais, independentemente de seu enquadramento socioeconômico, devendo o Estado estar comprometido com a preservação da dignidade material de todas as pessoas. Assim, esse mínimo incondicional não pode ser suprimido, com base na sua dignidade que lhe é própria.

E desta forma, acerca do debate tributário, resta saber quais os parâmetros constitucionais são adotados nesse contexto.

Para Marco Aurélio Greco (2011, p.15):

A mudança política, social e fática levou a uma mudança de mentalidade que repercutiu no modo pelo qual devem ser compreendidas as condutas do Fisco e do contribuinte. Em relação à conduta do Fisco questionam-se as finalidades de sua ação, bem como a destinação e a aplicação dos recursos arrecadados e sua compatibilidade efetiva com as políticas públicas que devem subsidiar; em relação à conduta do contribuinte questiona-se a existência de um fundamento substancial que a justifique (razão ou motivo para o exercício da liberdade de contratar).

A vista do Direito Tributário, sabe-se que a arrecadação de tributos garante ao Estado os meios necessários para custear suas ações em prol do bem comum, sendo esta, em última análise, a própria razão de ser do Estado. O dever de contribuir é inerente e inato à qualidade da pessoa como ser social, um pressuposto constitucional.

O fundamento jurídico dos deveres fundamentais, dentre os quais o de contribuir para as despesas públicas, decorre de sua previsão constitucional. Cabendo ao legislador infraconstitucional estabelecer os deveres legais. Tais deveres estão formal e materialmente limitados pela própria Constituição, mormente pelos princípios da legalidade, da segurança jurídica, da igualdade e da capacidade contributiva. Surge então a noção de cidadania, e que o pagamento de impostos é um direito desse cidadão, uma contrapartida pela participação no espaço público.

Nesse sentido, Portella (2009, p. 187) define o tributo como: “o dever determinado pela Constituição no espaço aberto à liberdade e pela declaração de direitos fundamentais. Dessa forma, o tributo não é considerado mera obrigação criada por lei, e sim, dever fundamental criado pela Constituição".

Entretanto, ao passo que existe o dever de pagar tributos, há, por outro lado, a vinculação do Estado a um dever específico de respeito, de proteção e de promoção dos direitos 
fundamentais. Essa força vinculativa dirige-se, em primeiro lugar, ao legislador, obrigado a realizar certas tarefas, a respeitar limites e a acatar proibições, conforme valores constitucionalmente definidos.

Mesmo uma ordem constitucional democrática necessita de direitos de defesa, na medida em que também a democracia não deixa de ser exercício de poder dos homens sobre homens, estando exposta às possibilidades do abuso de poder e da prática de injustiças (PEZZI, 2008).

A imposição tributária descabida abala a liberdade e o direito de propriedade, além de outros direitos fundamentais. Sendo imprescindível o justo equilíbrio dos ônus tributário pelo legislador. Neste diapasão, a função do princípio da dignidade da pessoa humana é estabelecer critérios estáveis para afastar eventuais arbitrariedades cometidas pelo Estado contra o ser humano.

Não existe um critério de justiça uniforme para todo o direito. O Direito Tributário possui um modo particular de realização da justiça. As leis fiscais possuem princípios peculiares à matéria fiscal, sua relação entre justiça e princípios é inseparável, sendo por exemplo, muito reconhecida aplicação dos princípios da igualdade e da capacidade contributiva.

No âmbito do Direito Tributário, os direitos fundamentais se constituem num instrumento imprescindível de defesa da cidadania, pois impedem que a ação estatal seja exercida em desconformidade com a constituição, visando assegurar ao cidadão a proteção contra o exercício arbitrário do poder, relativamente à exigência de tributos.

O rol de princípios elencados no artigo 150 e seguintes da Constituição Federal foram criados para tutelar o contribuinte contra eventual abuso por parte do Estado, objetivando a aplicação do principio da dignidade humana visando garantir os seus direitos. Desse modo, o Estado não apenas deve se abster da prática de atos que possam ferir a dignidade da pessoa humana como também deve promover esta dignidade através de ações que garantam, dentre outros, um mínimo existencial para cada ser humano.

A dignidade da pessoa humana em matéria tributária deve direcionar o Estado, tanto no sentido de garantir que todos venham a contribuir de forma igualitária para o custeio das despesas na justa medida de suas capacidades e com o mínimo existencial assegurado, quanto orienta-lo para que realize seus fins direcionando os gastos públicos prioritariamente para a promoção do bem-estar do ser humano, garantindo sua dignidade e a proteção de seus direitos individuais.

Via de regra, o tributo serve como suporte econômico e financeiro para as despesas à realização das tarefas do Estado. 
$\mathrm{Na}$ incumbência de guardião da Carta Magna, o Estado e seus órgãos públicos estão estritamente vinculados ao princípio da dignidade da pessoa humana, devendo considera-lo como guia em suas todas as suas ações e em todas as esferas.

Ao Estado são atribuídos diversos deveres de abstenção. Em nome da dignidade humana, exige-se que conserve o mínimo necessário à existência digna do contribuinte, assim como a livre iniciativa e a livre concorrência demandam que respeite o poder de direção das atividades privadas (ÁVILA, 2004, p.72).

Para Alexandra Cristina GiacometPezzi, da tributação são extraídos os recursos que lhe permitem atender aos reclamos da população, de modo que todos alcancem um mínimo em dignidade. Mas, para isso, é necessário que a ação estatal seja planejada e que os gastos públicos sejam submetidos a um controle rigoroso. Recordes de receita se esvaem facilmente quando o fim maior do Estado não é o cumprimento das tarefas impostas pela dignidade (PEZZI, 2008, p. 162).

Através das regras é que se concretizam os princípios, portanto, uma das mais relevantes funções afetas ao princípio da dignidade da pessoa humana, em matéria de Direito Tributário, é a de estabelecer critérios seguros de demarcação de imunidades tributárias, evidenciando, assim, um necessário confronto entre o crescente poder tributário do Estado e a efetiva proteção à inviolabilidade dos direitos do cidadão-contribuinte. $\mathrm{O}$ princípio da dignidade da pessoa humana serve como elemento de proteção dos direitos fundamentais contra medidas restritivas adotadas quer pelo administrador, quer pelo legislador. Ela fixa o núcleo essencial do direito, imunizandoo contra o agir estatal.

É evidente que o Estado deve prestar mais a alguns indivíduos, a fim de que adquiram condições dignas de se desenvolverem como pessoas. O custeio das prestações sociais básicas que permitem o atingimento desse status se dá, fundamentalmente, pelos recursos advindos da tributação. Na medida em que os detentores de maior potencial de riqueza contribuem em maior escala, opera-se a função redistributiva. Já dizia John Rawls (2002, p.26) que “A justiça social é o princípio da prudência aplicado a uma concepção somática do bem-estar do grupo".

A almejada justiça social é extraída do preambulo da Constituição brasileira onde se lê que o Estado Democrático deve "assegurar o exercício dos direitos sociais", os quais, junto com o bem-estar e a justiça, são os "valores supremos de uma sociedade fraterna, pluralista e sem preconceitos".

Um extenso rol a partir do artigo $1^{\circ}$ ao artigo $5^{\circ}$, projeta inúmeros fundamentos e objetivos fundamentais da República, destacando-se a cidadania, a dignidade humana, os valores sociais do trabalho e da livre iniciativa, a construção de uma sociedade livre, justa e solidária, o 
desenvolvimento nacional; erradicação da pobreza e a marginalização e a redução as desigualdades sociais e regionais; promoção do bem de todos, sem preconceitos de origem, raça, sexo, cor, idade e quaisquer outras formas de discriminação. Há uma lista de direitos individuais e coletivos, direitos sociais, ordem social e econômica.

A análise Plauto Faraco de Azevedo (1998, p.49) denota que a Constituição adotou o conceito aristotélico de justiça distributiva, em que a equidade é o instrumento de distribuição de direitos e obrigações, tendente à redução das desigualdades. Só haverá justiça social onde a distribuição contemplar os mais necessitados com um número maior de benefícios.

Contudo, inevitável reconhecer que o Estado brasileiro possui um grave problema no que tange à elaboração de um plano nacional de desenvolvimento que alcance as desigualdades regionais, por meio de políticas públicas conjuntas e de compensações de tais disparidades.

Por esta razão, a transferências de recursos entre os entes federativos é uma redistribuição de renda e não uma expressão de bondade dos mais ricos aos mais pobres. No entanto, é sabido apenas a transferência de receitas por si só não resolveriam os problemas gerados pelas desigualdades regionais, sendo primordial um programa econômico entre a União e os demais entes federados.

Outro ponto importante de se destacar é que as normas tributárias sempre foram alvo de grande rejeição social. Isso se explica pelo fato de que raramente na história humana a tributação se mostrou justa (TÔRRES, 2005, p. 32).

Na medida em que aumentam os tributos, aumentam a propensão do Estado para gastar. Deve haver uma repartição tributária justa e a transparência à tributação.

Sacha Calmon (2004, p. 196) se exalta ao afirmar, em face da vasta gama de princípios constitucionais tributários, que todo o Direito Tributário brasileiro seria controlável pelo Supremo Tribunal Federal a partir deles.

Nesta acepção, é fundamental um plano estratégico pelo Estado, visto que, a carga tributária não pode ser onerosa demais ou utilizada para a cobertura de déficits causados pela má administração das finanças pelo ente público. A ponderação exige uma justa maneira global no tratamento com o contribuinte, e os critérios devem ser racionais e planejados. Infelizmente, no Brasil, é histórico o déficit de prestações sociais.

Não se pode olvidar também que legislação constitucional de tutela especifica dos princípios basilares mencionados neste trabalho carece muitas vezes de complementação pelo direito ordinário.

Sob este prisma, compete ao Estado recriar as condições para que todos possam usufruir dos mesmos direitos e cumprir os mesmos deveres, equilibrando as desigualdades, e deixando 
com que a igualdade possibilite oportunidades e condições reais de vida. De nada adianta a mera igualdade perante a lei, é indispensável que a legalidade esteja unida a igualdade. Desta forma, seria vislumbrada uma politica de justiça social, com a efetivação dos direitos fundamentais.

O que a implementação de políticas públicas visa é permitir o pleno exercício de uma dignidade preexistente, de forma que todos vivam em clima de liberdade e de segurança. Sua efetiva realização depende do grau de reconhecimento e proteção outorgado por cada ordem jurídica. Isso porque, no Estado moderno,

os direitos fundamentais clássicos ligados à liberdade estão cada vez mais fortemente dependentes da prestação de determinados serviços públicos, sem os quais o indivíduo sofre sérias ameaças. Os direitos fundamentais de defesa somente podem ser eficazes quando protegem, ao mesmo tempo, as condições materiais mínimas necessárias para a possibilidade da sua realização. Especialmente na área dos direitos básicos da vida e da integridade física, as prestações positivas do Estado para a sua defesa não podem ficar na dependência da viabilidade orçamentária (KRELL, 1999, p. 245).

Acerca dessas prestações, transcreve-se a lição de Pérez Luño, no sentido de que:

No Estado de Direito os direitos fundamentais não aparecem como concessões, senão como corolário da soberania popular, através do princípio de que a lei não implica apenas um dever, mas um direito para o indivíduo (LUÑO, 1999, p. 212).

Por tais razões, se pode afirmar que a norma jurídico-tributária no Estado Democrático de Direito fundou-se para consolidar a segurança jurídica das leis, e principalmente a dignidade humana, formando os pilares essenciais de um conjunto de proposições voltadas a concepções tributárias.

\section{CONCLUSÃO}

O princípio da dignidade da pessoa humana constitui uma categoria axiológica aberta, e não pode ser conceituado restritivamente, visto a diversidade de valores inseridos nas diversas sociedades democráticas, seria um limitador a aplicação da dignidade humana.

O dever de pagar tributos é fundamental, visto que o Estado Democrático de Direito necessita de recursos para o seu desenvolvimento, funcionamento, e custeio, sem o qual restaria inviabilizado a efetiva proteção da dignidade da pessoa humana e seus direitos fundamentais decorrentes.

De fato, a atividade estatal é essencial para a promoção e manutenção dos princípios fundamentais garantidores da dignidade da pessoa humana, o próprio estabelecimento de normas 
protetivas em matéria fiscal, tais como a vedação ao confisco, a igualdade, a estrita, a legalidade e a capacidade contributiva, com vistas ao estabelecimento de uma carga tributária que promova o livre desenvolvimento do contribuinte, constituem importantes limitações ao poder de tributar e instrumentos de preservação da dignidade da pessoa humana.

Também não pode se olvidar que, em que pese a função arrecadatória dos tributos para o bom funcionamento de um Estado, o que se constata no Brasil é uma excessiva ineficácia em diversos setores estatais, na medida em que a arrecadação é alta, entretanto, o investimento em prol do contribuinte é baixa, o que dificulta a garantia de seus direitos fundamentais.

Os direitos fundamentais são merecedores de proteção especial, visto proporcionar uma vida livre, justa e solidária como determina um dos objetivos fundamentais da República.

Assim, de acordo com o presente trabalho, verificou-se que os princípios fundamentais básicos funcionam como fundamentos interpretativos da Constituição, sendo uma de suas finalidades principais a proteção dos direitos dos cidadãos contra restrições arbitrárias. Desta forma, não pode ser tolerada pelo sistema constitucional qualquer afronta ao princípio da dignidade da pessoa humana, sob pena de se privar o cidadão-contribuinte da justa tributação, em consonância com as prerrogativas dos direitos fundamentais.

\section{REFERÊNCIAS}

ATALIBA, Geraldo. República e Constituição. 2. ed. atualizada. São Paulo: Malheiros, 1998.

ÁVILA, Humberto. A distinção entre princípios e regras e a redefinição do dever de proporcionalidade. Revista de Direito Administrativo, Rio de Janeiro, n. 215, jan.-mar. 199.

Humberto ÁVILA. Sistema Constitucional Tributário. São Paulo: Saraiva, 2004.

BARROSO, Luís Roberto; BARCELlOS, Ana Paula de. O começo da história: a nova interpretação constitucional e o papel dos princípios no direito brasileiro. In: BONAVIDES, Paulo (Org.). Revista Latino-Americana de Estudos Constitucionais. Belo Horizonte. n.2, julho/dezembro, 2003. 
BARZOTTO, Luís Fernando. Os direitos humanos como direitos subjetivos: da dogmática jurídica à ética. Revista Direito e Justiça da Faculdade de Direito da PUCRS, Porto Alegre, v. 31, ano XXVII , n. 1, julho 2005).

BOGO, Luciano Alaor. Elisão tributária: licitude e abuso de direito. Curitiba: Juruá, 2006.

BUFFON, Marciano. Tributação e dignidade humana: entre os direitos e deveres fundamentais. Porto Alegre: Livraria do Advogado, 2009.

CARVALHO, Kildare Gonçalves. Direito constitucional. 14. ed., rev. atual. e ampl. Belo Horizonte: Del Rey, 2008.

CARVAlHO, Paulo de Barros. Curso de Direito Tributário. $18^{\mathrm{a}}$ ed. rev. e atual. São Paulo: Saraiva, 2007.

COÊLHO, Sacha Calmon Navarro. Curso direito tributário brasileiro. $16^{\mathrm{a}}$ ed. rev. e atual. Rio de Janeiro: Forense, 2018.

COÊLHO, Sacha Calmon Navarro. Curso de direito tributário brasileiro. $7^{\mathrm{a}}$ ed. Rio de Janeiro: Forense, 2004.

JÚNIOR, Luiz Emygdio F. da Rosa. Manual de Direito Financeiro e Tributário. $10^{\mathrm{a}}$ ed. Rio de Janeiro: Renovar, 1995.

GOMES, Sérgio Alves. Hermenêutica constitucional: um contributo à construção do Estado Democrático de Direito. Curitiba: Juruá, 2008.

KRELL, Andréas J.. Realização dos direitos fundamentais sociais mediante controle judicial da prestação dos serviços públicos básicos (uma visão comparativa). Revista de Informação Legislativa, Brasília, ano 36, n. 144, out.-dez. 1999.

LUÑO, Antonio Enrique Pérez. Derechos humanos, Estado de derecho y Constitucion. 6. ed. Madri: Tecnos, 1999. 
MACHADO. Hugo de Brito. Curso de direito tributário. 23. ed. São Paulo: Malheiros. 2003.

PEZZI, Alexandra Cristina Giacomet. Dignidade da pessoahumana: mínimo existencial e limites à tributação no estado democrático de direito. Curitiba: Juruá, 2008.

PORTELLA, Simone de Sá. As imunidades tributárias na jurisprudência do STF. São Paulo: Baraúna, 2009.

SARLET, Ingo Wolfgang. A Eficácia dos Direitos Fundamentais. 4. ed. Porto Alegre: Livraria do Advogado, 2004.

SARLET, Ingo Wolfgang. A Eficácia dos Direitos Fundamentais. 4. ed. Porto Alegre: Livraria do Advogado, 2004.

STRECK, Lenio Luiz; MORAIS, José Luis Bolzan de. Ciência Política e Teoria Geral do Estado. 2a ed. Porto Alegre: Livraria do Advogado, 2001.

TORRES, Ricardo Lobo. Tratado de direito constitucional, financeiro e tributário. Os direitos humanos e a tributação: imunidades e isonomia. $3^{\text {a }} \mathrm{ed}$. V. III. Rio de Janeiro: Renovar, 2005.

TORRES, Ricardo Lobo. O poder de Tributar no Estado Democrático de Direito. In: Direito e poder: nas instituições e nos valores do público e do privado contemporâneos. TÔRRES, Heleno Taveira (Coord.). Barueri: Manole, 2005.

LÔBO, Paulo Luiz Netto. Boletim Instituto Brasileiro de Direito de família, n. 4, set.-out. 2007.

FACHIN, Zulmar. Curso de direito constitucional. 3. ed., rev., atual. e ampl. São Paulo: Método, 2008.

RAWLS, John. Liberalismo Político. Trad. Sergio René Madero Báez. México: Fondo de Cultura Econômica, 1992. 
RAWLS, John. Uma teoria da justiça. São Paulo: Martins Fontes, 2002.

ROUSSEAU, Jean J. O contrato social. Trad. de Antônio de P. Machado. 5. ed. São Paulo: Ed. Edigraf Ltda, 1958.

Wertbetrachtungin RechtundihreGrenzen, apud BONAVIDES, Paulo. Curso de direito constitucional. 15. ed. São Paulo: Malheiros, 2004. 